\title{
Altered Hyperlipidemia, Hepatic Steatosis, and Hepatic Peroxisome Proliferator-Activated Receptors in Rats with Intake of Tart Cherry
}

\author{
E. Mitchell Seymour, ${ }^{1,2}$ Andrew A.M. Singer, ${ }^{2}$ Ara Kirakosyan, ${ }^{2}$ \\ Daniel E. Urcuyo-Llanes, ${ }^{2}$ Peter B. Kaufman, ${ }^{2}$ and Steven F. Bolling ${ }^{2}$ \\ ${ }^{1}$ Department of Food Science and Human Nutrition, Michigan State University, East Lansing; and ${ }^{2}$ Section of \\ Cardiac Surgery and the Michigan Integrative Medicine Program, University of Michigan Health System, \\ Ann Arbor, Michigan
}

\begin{abstract}
Elevated plasma lipids, glucose, insulin, and fatty liver are among components of metabolic syndrome, a phenotypic pattern that typically precedes the development of Type 2 diabetes. Animal studies show that intake of anthocyanins reduces hyperlipidemia, obesity, and atherosclerosis and that anthocyanin-rich extracts may exert these effects in association with altered activity of tissue peroxisome proliferator-activated receptors (PPARs). However, studies are lacking to test this correlation using physiologically relevant, whole food sources of anthocyanins. Tart cherries are a rich source of anthocyanins, and whole cherry fruit intake may also affect hyperlipidemia and/or affect tissue PPARs. This hypothesis was tested in the Dahl Salt-Sensitive rat having insulin resistance and hyperlipidemia. For 90 days, Dahl rats were pair-fed AIN-76a-based diets supplemented with either $1 \%$ (wt:wt) freeze-dried whole tart cherry or with $0.85 \%$ additional carbohydrate to match macronutrient and calorie provision. After 90 days, the cherry-enriched diet was associated with reduced fasting blood glucose, hyperlipidemia, hyperinsulinemia, and reduced fatty liver. The cherry diet was also associated with significantly enhanced hepatic PPAR- $\alpha$ mRNA, enhanced hepatic PPAR- $\alpha$ target acyl-coenzyme A oxidase mRNA and activity, and increased plasma antioxidant capacity. In conclusion, physiologically relevant tart cherry consumption reduced several phenotypic risk factors that are associated with risk for metabolic syndrome and Type 2 diabetes. Tart cherries may represent a whole food research model of the health effects of anthocyanin-rich foods and may possess nutraceutical value against risk factors for metabolic syndrome and its clinical sequelae.
\end{abstract}

KEY WORDS: • anthocyanin • diabetes • diet

\section{INTRODUCTION}

$\mathbf{H}$ YPERLIPIDEMIA, hyperinsulinemia, and elevated fasting blood glucose are among several clinical parameters of prediabetes or the "metabolic syndrome" and are positively correlated with the incidence of Type 2 diabetes and cardiovascular disease. The American Heart Association estimates that $25 \%$ of Americans display indices of metabolic syndrome, which can progress silently towards frank diabetes and heart disease. ${ }^{1}$ Fruit and vegetable intake is inversely correlated with morbidity and mortality. Furthermore, fruits and vegetables contain non-nutritive phytochemicals that may contribute to their health-promoting effects.

Anthocyanins are one of the major subclasses of phytochemical flavonoids, and they are principally found in

Manuscript received 9 November 2007. Revision accepted 13 January 2008.

Address reprint requests to: E. Mitchell Seymour, Section of Cardiac Surgery and the Michigan Integrative Medicine Program, University of Michigan Health System, B560 MSRB2 0686, 1500 West Medical Center Drive, Ann Arbor, MI 48109, E-mail: seymoure@umich.edu red-, blue-, and purple-pigmented fruits and vegetables. Several studies have suggested that several botanical extracts, including anthocyanin-rich extracts, modify lipid metabolism in vitro and can reduce hyperlipidemia in vivo. ${ }^{2-7}$ While reductionistic approaches to phytochemical research are valuable for mechanistic studies, the results should be paired with physiologically relevant, whole foods approaches to assess biologic relevance.

Isolated anthocyanins and anthocyanin-rich extracts were recently shown to modify the activity of peroxisome proliferator-activated receptors (PPARs). ${ }^{8}, 9$ PPAR is a transcription factor that controls genes that modify blood lipoprotein metabolism and tissue lipolysis. Depending on the targeted PPAR isoform, PPAR agonists can alter blood lipids, alter fat metabolism in tissues, and improve insulin resistance. ${ }^{10-12}$ Pharmaceutical PPAR agonist drugs reduce plasma cholesterol and triglycerides (PPAR- $\alpha$ agonist drugs, like fibrates) and improve insulin sensitivity (PPAR- $\gamma$ agonist drugs, like thiazolidinediones). While concentrated anthocyanin-rich extracts have recently demonstrated effects on PPAR isoform expression, it is unknown if physiologi- 
cally relevant doses of anthocyanin-rich whole foods could exert a nutraceutical effect on PPAR.

This gap in knowledge is addressed herein using daily diet enrichment with whole tart cherry powder. Tart cherries (Prunus cerasus) are a rich source of anthocyanins. ${ }^{13,14}$ Given the observed effects of anthocyanins on PPARs and the effect of PPAR agonists on metabolic syndrome, we tested the hypothesis that intake of tart cherry-supplemented diet would modify indices of metabolic syndrome and modify PPARs in the Dahl-Salt Sensitive (Dahl-SS) rat model. Dahl-SS animals develop hyperlipidemia and insulin resistance in the absence of obesity. ${ }^{15-18}$ Dahl-SS rats display both enhanced hepatic very low-density lipoprotein (VLDL) production and reduced VLDL-triglyceride clearance via reduced lipoprotein lipase activity. ${ }^{16,17,19,20}$ Importantly, Dahl-SS rat hyperlipidemia and insulin resistance are significantly improved by PPAR agonist drugs. ${ }^{21-24}$

We tested the health effect of subchronic (90-day) diet provision of whole tart cherry powder at $1 \%$ of the diet by weight. We expect that cherry-enriched diets would decrease plasma hyperlipidemia. Because the liver is the primary source of lipogenesis in rodent models, we measured hepatic lipid content as well as the levels of PPAR isoforms and of PPAR-related transcripts involved in lipid balance. Acylcoenzyme A (CoA) oxidase (ACO) mRNA served as a

Table 1. Profiles of Cherry-Supplemented Diet (CHE) And Carboydrate-Supplemented Control Diet (CON)

\begin{tabular}{lcc}
\hline & $C H E$ & $C O N$ \\
\hline \% of diet & & \\
Total protein & 21.0 & 20.0 \\
Total carbohydrate & 65.4 & 65.4 \\
Total fat & 5.0 & 5.0 \\
kcal/g of diet & 3.9 & 3.9 \\
g/kg diet & & \\
Casein & 198 & 198 \\
Protein from cherry & 0.09 & 0 \\
DL-Methionine & 2.9 & 2.9 \\
Cornstarch & 148.5 & 148.5 \\
Sucrose & 497.7 & 497.7 \\
Sugar from cherry & 7.3 & 0 \\
Dextrose & 0 & 3.6 \\
Fructose & 0 & 3.6 \\
Cellulose & 49.5 & 49.6 \\
Fiber from cherry & 0.9 & 0 \\
Corn oil & 49.5 & 49.6 \\
Choline bitartrate & 1.9 & 1.9 \\
Cholesterol & 0 & 10 \\
AIN76a vitamin mix & 10 & 35 \\
AIN 76a mineral mix & 35 & 0 \\
Vitamin C & 0.002 & 0 \\
Vitamin A & $441.4 \mathrm{IU}$ & 0 \\
$\alpha$-Carotene & $44 \mathrm{RE}$ & 0 \\
Phosphorus & 0.013 & 0 \\
Potassium & 0.11 & 0.015 \\
Sodium & & \\
\hline & & \\
\hline & &
\end{tabular}

IU, International Units; RE, retinol equivalence.
Table 2. Tart Cherry Powder Phytochemical Profile as Measured by LC-MS

\begin{tabular}{lc}
\hline & $m g / g$ dry weight \\
\hline Cyanidin 3-sophoroside & 0.0041 \\
Cyanidin 3-glucosylrutinoside & 0.3757 \\
Cyanidin 3-glucoside & 0.0071 \\
Cyanidin 3-rutinoside & 0.2261 \\
Other cyanidins & 0.0051 \\
Peonidin 3-glucoside & 0.0388 \\
Pelargonidin & 0.0086 \\
Isorhamnetin rutinoside & 0.1766 \\
Quercetin & 0.2926 \\
Kaempferol & 0.0859 \\
Melatonin & 0.0007 \\
\hline
\end{tabular}

marker for hepatic PPAR- $\alpha$ activation, while fatty acid synthase (FAS) mRNA served as a marker of hepatic PPAR- $\gamma$ activation.

\section{MATERIALS AND METHODS}

\section{Animal care}

Male Dahl-SS Rats (Rapp strain, 5 weeks old) were acquired from Harlan (Indianapolis, IN) and were housed three per cage. Rats were housed on 12-hour light:dark cycles. At 6 weeks of age, rats were randomized to two groups $(n=$ 12 each): $1 \%$ cherry powder by weight or $0.85 \%$ additional carbohydrate by weight (dextrose:fructose 1:1) to control for the additional carbohydrate provided by the cherry powder. The cherry product employed was a freeze-dried powder from individually quick frozen (IQF) Montmorency tart cherries, harvested in northern Michigan and prepared by VanDrunen Farms (Momence, IL). Nutrient analysis (Table 1) was conducted by VanDrunen Farms and its subsidiary Futureceuticals (Momence), and further anthocyanin analysis was conducted by our group (Table 2) as described below. Cherry powder or the dextrose:fructose mixture was incorporated into powdered AIN-76a diet (Research Diets, New Brunswick, NJ). Diets were mixed weekly, vacuumsealed, and stored at $4^{\circ} \mathrm{C}$. Rats were pair-fed $20 \mathrm{~g}$ of diet per head per day, and water was provided ad libitum. This protocol was approved by the University of Michigan's University Committee on the Use and Care of Animals.

\section{Product characterization: extraction and liquid chromatography-mass spectrometry (LC-MS) analysis of tart cherry powder}

IQF tart cherry powder $(1 \mathrm{~g})$ was extracted with $10 \mathrm{~mL}$ of methanol/water/acetic acid (85:15:0.5 by volume) in a 15$\mathrm{mL}$ screw-cap tube and shaken overnight in the dark at $4^{\circ} \mathrm{C}$. The sample was vortex-mixed and then sonicated for 10 minutes at $25^{\circ} \mathrm{C}$. After filtration (pore size, $0.45 \mu \mathrm{m}$ ), the extract was ready for LC-MS analysis. An Alliance 2695 
high-performance liquid chromatograph (Waters, Milford, MA) was used to generate a binary gradient with $0.05 \%$ trifluoroacetic acid in water as the aqueous solvent (A) and $0.05 \%$ trifluoroacetic acid in acetonitrile as the organic modifier (B). Chromatographic separation was achieved with a Gemini 5- $\mu \mathrm{m} \mathrm{C18} \mathrm{150-} \times 2.00-\mathrm{mm}$ (Phenomenex, Torrance, $\mathrm{CA}$ ) reverse-phase column held at $35^{\circ} \mathrm{C}$ using a flow rate of $0.19 \mathrm{~mL} /$ minute. The column was initially equilibrated to $8 \% \mathrm{~B}$, increased to $18 \% \mathrm{~B}$ over 10 minutes, $28 \%$ $\mathrm{B}$ over the next 8 minutes, $40 \% \mathrm{~B}$ in 1 minute, and $60 \% \mathrm{~B}$ in 3 minutes, and then returned to initial conditions. The sample chamber was cooled to $10^{\circ} \mathrm{C}$, and the injection volume was $10 \mu \mathrm{L}$. Effluent from the high-performance liquid chromatography column was directed into the electrospray ionization probe of a TSQ Quantum Ultra AM triple quadrupole mass spectrometer (ThermoFinnigan, San Jose, CA). Positive ions were generated with the following parameters: spray voltage, $3,000 \mathrm{~V}$; sheath gas setting 40 ; auxiliary gas setting 10; capillary temperature $250^{\circ} \mathrm{C}$. Tube lens voltages were optimized for each compound. Data were collected in centroid mode. Single reaction monitoring was used for mass analysis and quantification. Data analysis was performed with Xcalibur ${ }^{\mathrm{TM}}$ quantitation software (version 1.4 SR1, ThermoFinnigan).

\section{Biological sample collection}

After 90 days of feeding, rats were fasted for 18 hours and then sacrificed by decapitation, and trunk blood was collected. Heart, kidneys, and liver were harvested, blotted, and weighed. Whole blood was collected in $0.6-\mathrm{mL}$ capacity serum-separator tubes, allowed to clot at room temperature, and spun at 5,000 $\mathrm{g}$ for 7 minutes at $4^{\circ} \mathrm{C}$. Serum was aliquoted and stored at $-80^{\circ} \mathrm{C}$ until further analysis. Whole blood was collected in a 7-mL EDTA-Vacutainer ${ }^{\circledR}(\mathrm{BD}$, Franklin Lakes, $\mathrm{NJ}$ ) and spun at $4^{\circ} \mathrm{C}$ at $1,500 \mathrm{~g}$. Plasma was then aliquoted and stored at $-80^{\circ} \mathrm{C}$ until further analysis.

\section{Serum and plasma analysis}

Clinical chemistries were run on serum using the automated VetTest ${ }^{\circledR}$ Chemistry Analyzer (IDEXX Laboratories, Westbrook, ME). Plasma insulin and 8-isoprostane were measured by immunoassay (Cayman Chemical, Ann Arbor, MI) according to the manufacturer's instructions. Plasma antioxidant capacity was measured by the total antioxidant capacity assay (TAS, Randox Laboratories, Crumlin, UK) according to the manufacturer's instructions, but with volumes modified for high-throughput analysis using the microplate method as we have conducted and described previously. ${ }^{25}$

\section{Real-time polymerase chain reaction (PCR)}

Hepatic total RNA was isolated from three animals per group with Trizol reagent (Invitrogen, Carlsbad, CA) and subsequently further purified using the ArrayGrade ${ }^{\text {TM }}$ Total
RNA Isolation kit (SuperArray Bioscience, Frederick, MD), following the manufacturer's protocol. For real-time PCR, $3 \mu \mathrm{g}$ of hepatic total RNA from each rat was used to make first-strand cDNA. Real-time PCR assays were performed with $1 \mu \mathrm{L}$ of cDNA using RT2 Real-Time ${ }^{\mathrm{TM}}$ SYBR Green master mix (SuperArray) in the ABI Prism 7700 (Applied Biosystems, Foster City, CA). The rat-specific PPAR primer pairs were obtained from SuperArray (PPAR- $\alpha$, catalog number PPR44459A; PPAR- $\gamma$, catalog number PPR47599A; ACO, catalog number PPR48458A; FAS, catalog number PPR44358E). The sequence of rat $18 \mathrm{~S}$ primers was forward 5'-AGTCCCTGCCCTTTGTACACA$3^{\prime}$ and reverse 5'-GATCCGAGGGCCTCACTAAAC- $3^{\prime}$. Cycle threshold $(C t)$ was plotted as a standard curve for each target. For each gene, we ran an amplification efficiency validation experiment by creating a standard curve with six cDNA dilutions (1:2-1:64). The $\Delta C t$ ( $C t$ target gene $-C t$ $18 \mathrm{~S}$ rRNA) for each dilution was plotted versus the log amount of cDNA. The absolute value of the slope of these graphs did not exceed 0.1 for any of the target genes, indicating equal PCR efficiency. Relative expression was determined by the $\Delta \Delta C t$ method as described by Livak and Schmittgen. ${ }^{26} \Delta C t$ for each gene (averaged across three animals per group) was calculated relative to $18 \mathrm{~S}$ rRNA (averaged across three animals per group). $\Delta \Delta C t$ was then determined as $\Delta C t$ (group 2) minus $\Delta C t$ (group 1), where group 1 is the carbohydrate control and group 2 is the cherry experimental group, and the values were then back-transformed $\left(2^{-\Delta \Delta C t}\right)$ to calculate the relative abundance of each transcript in the cherry-treated rats compared to untreated carbohydrate control.

\section{Hepatic neutral lipid analysis}

Lipid was extracted from minced, frozen hepatic tissue as described by Folch et al. ${ }^{27}$ Following extraction, total cholesterol and triglyceride concentrations were measured using commercially available colorimetric cholesterol and triglyceride determination kits (Diagnostic Chemicals, Oxford, CT) following the manufacturer's instructions.

\section{Hepatic FAS and ACO activity}

All reagents used in the enzyme assays are pharmaceutical-grade from Sigma-Aldrich (St. Louis, MO). FAS enzyme activity was determined using a modification of a previously described assay. ${ }^{28}$ Briefly, frozen tissue was homogenized on ice in $0.1 M$ potassium phosphate buffer ( $\mathrm{pH} 7.0$ ) containing $8 \%$ sucrose, $1 \mathrm{~m} M$ EDTA (pH 8.0), and $20 \mathrm{mM} 2$ mercaptoethanol. Tissue was sonicated using a 30-second pulse of a Polytron (Brinkmann Instruments, Westbury, NY) at maximum speed. Homogenates were then centrifuged at $3,000 \mathrm{~g}$ for 10 minutes at $4^{\circ} \mathrm{C}$. For the FAS activity assay, $10 \mu \mathrm{L}$ of the supernatant was added to $80 \mu \mathrm{L}$ of assay buffer (2 mM EDTA [pH 8.0], $2 \mathrm{mM}$ dithiothreitol, and $0.4 \mathrm{mg} / \mathrm{mL}$ 
$\mathrm{NADPH}$ ), and the rate of NADPH oxidation at $30^{\circ} \mathrm{C}$ was monitored at $340 \mathrm{~nm}$ in a Pharmacia (Piscataway, NJ) Ultrospec 4300 Pro ultraviolet-visible spectrophotometer. One unit of FAS activity was determined by subtracting the $\mathrm{NADPH}$ oxidation rate from the rate after adding $10 \mu \mathrm{L}$ of $0.85 \mathrm{mg} / \mathrm{mL}$ malonyl-CoA, expressed as nanomoles of $\mathrm{NADPH}$ oxidized per minute at $37^{\circ} \mathrm{C}$ per milligram of total protein in the sample. For the ACO activity assay, a peroxisome-rich fraction was prepared form the whole cell homogenate as reported by Small et al. ${ }^{29}$ ACO activity was measured from the rate of palmitoyl-CoA-dependent $\mathrm{H}_{2} \mathrm{O}_{2}$ production coupled with dichlorofluorescein oxidation at $520 \mathrm{~nm}$. One unit of activity was defined as $1 \mathrm{nmol}$ of dichlorofluorescein oxidized/minute at $30^{\circ} \mathrm{C}$. Protein concentrations were determined using a BCA Protein Assay kit (Pierce, Rockford, IL).

\section{Statistical methods}

Differences in mRNA levels are shown as mean $\pm \mathrm{SD}$, as required by the $\Delta \Delta C t$ method as described by Livak and Schmittgen. ${ }^{26}$ All other values are expressed mean \pm SEM. Treatments were compared using a two-tailed Student's $t$ test. A value of $P<.05$ was considered statistically significant.

\section{RESULTS AND DISCUSSION}

Figure 1 indicates that cherry-enriched diets had no significant impact on body weight gain throughout the 90-day study. As shown in Table 3, fasting glucose, total cholesterol, triglyceride, and insulin are significantly reduced in the tart cherry-fed animals. The cherry diet did not significantly impact measures of liver function or other clinical chemistries, although blood urea nitrogen and amylase were reduced by cherry intake, perhaps suggesting improved renal function and pancreatic function, respectively. Tart cherries contain many phytochemicals with antioxidant potential, so we also tested diet effect on markers of oxidative

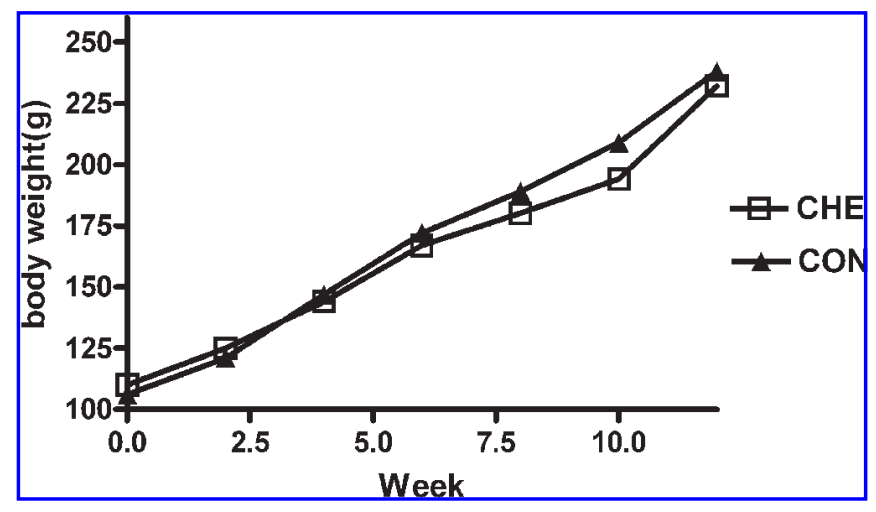

FIG. 1. Body weight change. Data are mean \pm SEM values $(n=$ 12 animals per group).
Table 3. Serum and Plasma Measures

\begin{tabular}{lcc}
\hline & CHE & $C O N$ \\
\hline Total cholesterol (mg/dL) & $75 \pm 4^{*}$ & $87 \pm 5$ \\
Total triglycerides (mg/dL) & $28 \pm 3^{*}$ & $34 \pm 3$ \\
Glucose (mg/dL) & $104 \pm 7^{*}$ & $119 \pm 8$ \\
Insulin (pg/mL) & $6.2 \pm 0.5^{*}$ & $7.8 \pm 0.5$ \\
Albumin (mg/dL) & $3.7 \pm 0.2$ & $3.5 \pm 0.2$ \\
Alkalin phosphatase (U/L) & $90 \pm 6$ & $92 \pm 5$ \\
ALT (U/L) & $61 \pm 4$ & $66 \pm 4$ \\
AST (U/L) & $187 \pm 12$ & $183 \pm 9$ \\
Amylase (U/L) & $1,502 \pm 13^{*}$ & $2,034 \pm 16$ \\
BUN (mg/dL) & $18 \pm 1^{*}$ & $24 \pm 2$ \\
Creatinin (mg/dL) & $0.5 \pm 0.1$ & $0.5 \pm 0.1$ \\
Total protein (g/dL) & $7 \pm 2$ & $7 \pm 1$ \\
Plasma TAS (mmol/L) & $0.94 \pm 0.05^{*}$ & $0.81 \pm 0.04$ \\
Plasma 8-isoprostane (pg/mL) & $48 \pm 3$ & $50 \pm 4$ \\
\hline
\end{tabular}

Data are mean \pm SEM values $(n=12$ per group). ALT, alanine aminotransferase; AST, aspartate aminotransferase; BUN, blood urea nitrogen; CHE, cherry-supplemented diet; CON, carbohydratesupplement control diet; TAS, total antioxidant status.

$* P<.05$ for comparison with $\mathrm{CON}$ value.

stress. Plasma antioxidant status was significantly improved by tart cherry, while the effect on the lipid oxidation marker 8 -isoprostane approached significance $(P=.08)$. The cherry diet was associated with a nonsignificant increase in heart, liver, and kidney weight relative to total body weight as compared to the control diet (Table 4).

Figure 2 shows that tart cherry diets significantly enhanced PPAR- $\alpha(P<.05)$ transcript level, while PPAR- $\gamma$ mRNA approached significance $(P=.08)$. Also, PPAR- $\alpha$ target ACO mRNA is strongly increased by the cherry-supplemented diet, and Figure 3 shows that ACO activity is also significantly enhanced. Hepatic PPAR- $\gamma$ target FAS mRNA was only moderately increased, and Figure 3 reveals a similarly small effect on hepatic FAS activity. Because ACO transcription is regulated by PPAR- $\alpha$ and because greater hepatic ACO activity reduces fat storage by promoting fat oxidation, the effect of cherry diet on enhanced hepatic ACO may explain the reduced hepatic triglyceride and cholesterol content observed in Table 4. The effects on both PPAR- $\alpha$ and PPAR $-\gamma$ correlate with moderately increased hepatic weight (Table 4), despite significantly reduced hepatic steatosis. These concurrent effects are also observed in rats given PPAR agonist drugs, which causes proliferation of cellular peroxisomes and increased organ weight. ${ }^{21-24}$

\section{Possible PPAR-related mechanisms}

The data relative to PPAR- $\alpha$ and $-\gamma$ isoforms presented here are supported by previous findings with concentrated anthocyanins or anthocyanin-rich botanical extracts. Munoz-Espada and Watkins ${ }^{8}$ showed in prostate cancer cells that exposure to cyanidin increases PPAR- $\gamma$ expression. Xia et al. ${ }^{9}$ showed in isolated macrophages that isolated antho- 
Table 4. Organ Weights and Liver Neutral Lipid Content

\begin{tabular}{lcc}
\hline & CHE & CON \\
\hline Heart weight/body weight $(\mathrm{g} / \mathrm{g} \times 100)$ & $3.7 \pm 0.2$ & $3.2 \pm 0.5$ \\
Liver weight/body weight $(\mathrm{g} / \mathrm{g} \times 100)$ & $27.5 \pm 3$ & $25.9 \pm 3$ \\
Kidney weight/body weight $(\mathrm{g} / \mathrm{g} \times 100)$ & $4.7 \pm 0.3$ & $4.5 \pm 0.3$ \\
Hepatic cholesterol $(\mu \mathrm{mol} / \mathrm{g})$ & $29 \pm 4^{*}$ & $43 \pm 4$ \\
Hepatic triglyceride $(\mu \mathrm{mol} / \mathrm{g})$ & $143 \pm 11^{*}$ & $185 \pm 25$ \\
\hline
\end{tabular}

Data are mean \pm SEM values ( $n=12$ per group). CHE, cherrysupplemented diet; CON, carbohydrate-supplement control diet.

$* P<.01$ for comparison with $\mathrm{CON}$ value.

cyanins induced cholesterol efflux in a PPAR- $\gamma$-dependent manner and that anthocyanins increased both PPAR- $\gamma$ expression and PPAR- $\gamma$ transcriptional activity in a dose-dependent fashion. Park et al. ${ }^{6}$ showed in diabetic mice that diets enriched with anthocyanin-rich mulberry leaf extract, Korean red ginseng, and banaba leaf extract reduced glucose, insulin, and triglyceride levels while increasing liver and fat tissue expression of PPAR- $\gamma$ and PPAR- $\alpha$ and liver lipoprotein lipase. It is compelling that the smaller dose of anthocyanins in the tart cherry-enriched diets used here retained biologic effects as compared to these earlier studies with concentrated extracts. It is possible that synergy among tart cherry phytochemicals or nutrients enhances anthocyanin bioavailability or efficacy.

In the current study, tart cherry-enriched diet was associated with significantly increased hepatic PPAR- $\alpha$ mRNA expression. PPAR $-\alpha$ is expressed largely in the liver and skeletal muscle and controls multiple target genes that are involved in lipid metabolism, including fatty acid oxidation and fatty acid transport. As such, PPAR- $\alpha$ agonist fibrate drugs are generally effective in lowering elevated plasma triglycerides and cholesterol. The effect of whole tart cherries on reduced hyperlipidemia and hepatic steatosis may be derived from one of more of these PPAR- $\alpha$-related mechanisms, such as the enhanced ACO expression observed here.

Tart cherry-enriched diets reduced fasting blood glucose and fasting insulin, and these effects may be due to anthocyanin-mediated agonism of PPAR- $\gamma$. PPAR $-\gamma$ is expressed in fat, muscle, and liver. In these tissues, PPAR- $\gamma$ regulates genes important for adipogenesis, lipid metabolism, and glucose control. As such, drugs that activate PPAR- $\gamma$ like the thiazolidinedione class have several effects that impact the pathogenesis of insulin resistance and Type 2 diabetes. ${ }^{30-36}$ The current study was mainly focused on hepatic effects of diet, and cherry diet-associated effects on hepatic PPAR- $\gamma$ mRNA approached significance. In the liver, PPAR- $\gamma$ agonist drugs up-regulate the expression of genes involved in lipid uptake and lipid storage, like FAS. ${ }^{37}$ Because we observed reduced rather than enhanced hepatic fat storage, the lipid oxidation-promoting effects of PPAR- $\alpha$ agonism appear to have overcome the effects of moderate PPAR- $\gamma$ agonism, but this assumption would need to be confirmed with more broad assessments of PPAR-related transcripts.

\section{Current study findings in context}

The study presented here uses a whole food model to test previous in vivo findings with concentrated, select anthocyanins or anthocyanin-rich botanical extracts. Tsuda et al. ${ }^{38}$ showed that in high-fat-fed mice, an anthocyaninrich extract from purple corn significantly reduced fat mass, hyperlipidemia, hyperinsulinemia, and blood glucose. The anthocyanin extract-enriched diet also significantly reduced tissue lipid accumulation and the activity of enzymes that promote fat storage. Xia et al. ${ }^{5,39}$ showed in atherosclerosis-prone mice that diets supplemented with an anthocyanin-rich extract from black rice significantly reduced atherosclerosis, total cholesterol, triglyceride, and tissue cholesterol and increased high-density lipoprotein (HDL). Finne-Nielsen et $a l .^{3}$ showed in rabbits that diets supplemented with anthocyanin-containing black currant juice significantly reduced VLDL and plasma total triglycerides while not significantly reducing total cholesterol. Interestingly, in this study, diets supplemented with the purified anthocyanins instead of anthocyanin-rich black currant juice increased cholesterol in a dose-dependent manner. Therefore, it may be concluded that the whole food provided the benefit rather than the isolated anthocyanins. Our findings in a whole food model reflect those obtained with anthocyanin-rich botanical extracts, suggesting that the anthocyanins in tart cherry may be the active constituent towards these metabolic syndrome phenotypes of interest. However, we cannot exclude the benefits of other cherry-derived phytochemicals including quercetin, melatonin, kaempferol, etc. These compounds may exert independent or synergistic effects towards our observed phenotypes.

Nair and colleagues recently conducted a study in mice using Cornelian "cherry." 40 This is not a true cherry of the agriculturally employed Prunus species, but is rather the red fruit of an ornamental dogwood tree (Cornus mas).

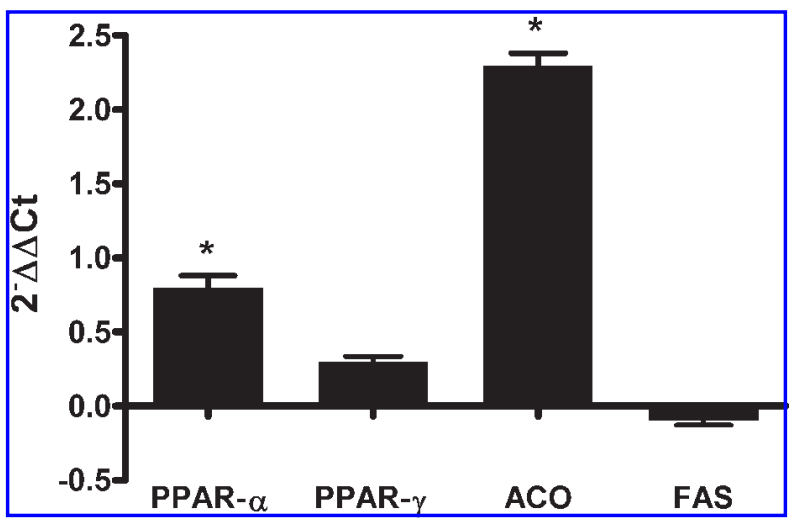

FIG. 2. Change in hepatic mRNA transcript levels in cherry-treated rats compared to the control group. Data are mean \pm SD values $(n=$ 3 per group). Threshold cycles of the transcripts in cherry-fed rat livers were internally normalized to the $18 \mathrm{~S}$ gene $(\Delta C t)$ and compared with control liver $(\Delta \Delta C t)$. $* P<.05$ versus $C O N$ value. 


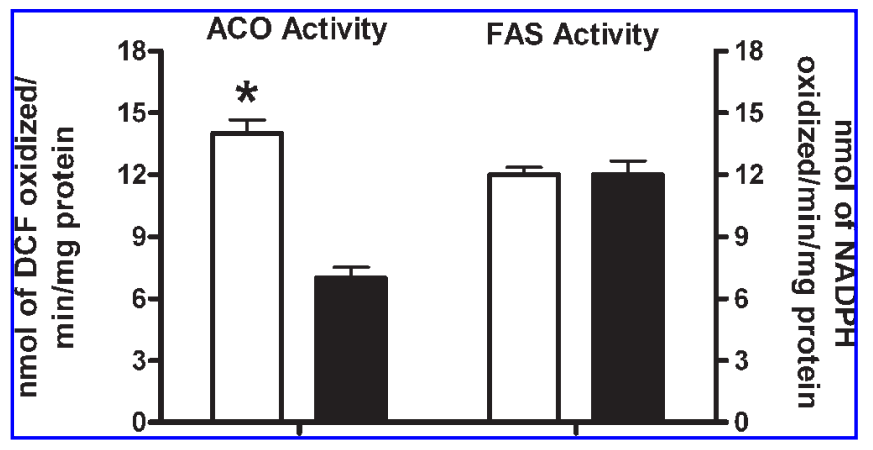

FIG. 3. Hepatic ACO and FAS activity. Data are mean \pm SEM values, tested from a pooled homogenate from 12 rats in each group. ACO activity is measured as nanomoles of dichlorofluorescein (DCF) oxidized/minute/mg of protein, and FAS activity is measured as nanomoles of NADPH oxidized/minute/mg of protein. Open bars are cherry-supplemented rats, while black bars are control rats. $* P<.05$ versus control value.

Jayaprakasam et al. ${ }^{40}$ reported that $\mathrm{C} 57 \mathrm{~B} 1 / 6$ mice ingesting Cornelian cherry-derived anthocyanin extract with a high-fat diet showed a significant decrease in weight gain and hepatic lipid accumulation while maintaining blood glucose control. However, mice fed the anthocyanin-free, high-fat diet gained weight and developed hyperglycemia, indicating the importance of the anthocyanin content to the treatment effect. The dose of Cornus anthocyanins used $(0.1 \%$ of diet by weight $)$ is fivefold higher than the total anthocyanins employed in the efficacious $1 \%$ tart cherry diet $(0.02 \%$ of diet by weight $)$ presented here. It is uncertain if a lower dose of Cornelian cherry anthocyanins would have retained a treatment effect, or if the whole tart cherry powder employed here provides a superior delivery mechanism for bioactive anthocyanins. For example, the whole cherry fruit contains several antioxidant constituents such as quercetin and melatonin that may stabilize the various anthocyanins. Additionally, these cherry phytochemicals may work synergistically in vivo with the anthocyanins.

A recent well-designed clinical trial tested the health effects of sweet cherry (rather than tart cherry) consumption in healthy men and women. ${ }^{41}$ Subjects consumed $\sim 45$ pitted Bing sweet cherries for 28 days, after which they were examined for changes in low-density lipoprotein (LDL), HDL, VLDL, insulin, and blood glucose. Plasma concentrations for total cholesterol, LDL-cholesterol, HDL-cholesterol, triglyceride, and the total cholesterol:HDL-cholesterol ratio were not influenced by cherry intake. The particle sizes for VLDL, LDL, and HDL were similarly not affected by cherry consumption. Fasting blood glucose concentrations were also not affected, but insulin was slightly elevated by sweet cherry intake. There could be several explanations for the different results between the current tart cherry study and this human sweet cherry study. The human subjects were healthy and did not display risk factors for metabolic syndrome; they had normal blood lipids, normal fasting glu- cose, and normal fasting insulin. However, sweet cherry diet effects on these parameters might only be observable in subjects/animals with or at risk for metabolic syndrome, such as the Dahl-SS rat. In addition, sweet cherries typically have lower total anthocyanin levels than tart cherries. It is hypothesized that the lower $\mathrm{pH}$ of the tart cherries stabilizes and prolongs anthocyanin integrity. In addition, the 28-day intervention with sweet cherry may not have been sufficient to observe a treatment effect and/or limited by the small number of test subjects $(n=18)$.

\section{Study limitations and future directions}

Bioequivalency between rodents and humans is not known because of species differences and differences in metabolic rates. Therefore, dosage was calculated using a conversion factor based upon the average difference in average adult human and adult rat body weight (250-fold difference). The IQF powder equivalent of 60 fresh cherries equals $\sim 45 \mathrm{~g}$ because of loss of weight on drying, so the rodent equivalent dose was calculated to be $45 \mathrm{~g} / 250$, or $\sim 200 \mathrm{mg}$ of powder/day. Given the average AIN-76a ad libitum intake of $20 \mathrm{~g} /$ day (determined in our preliminary studies with the Dahl-SS rat ${ }^{42}$ ), $200 \mathrm{mg}$ of cherry powder/day represents $1 \%$ of the daily diet. Other methods of bioequivalency determination may lead to different "dose" estimations to test for relevance to human diets.

We did not include measures of PPAR- $\gamma$ mRNA in other tissues involved in insulin sensitivity/resistance like skeletal muscle ${ }^{36}$ or adipose tissue. We are currently pursuing these end points, because the PPAR- $\gamma$ isoform is more abundant in these tissues than it is in the liver. Also, the tissue distribution of PPAR isoforms in rats and humans is different: the rat has relatively greater hepatic PPAR- $\alpha$ expression, while human liver shows higher PPAR- $\gamma$ expression. As such, the tart cherry-associated effects observed here may be more pronounced than would be observed in humans. While our study revealed changes in total triglyceride and total cholesterol, the altered lipoprotein fractions (HDL, LDL, and VLDL) responsible for this change are not known. In addition, while cholesterol-rich LDL is the prominent lipoprotein in humans, HDL is the prominent lipoprotein in rats. For clinical relevance, human or primate studies are needed to identify cherry-mediated effects in specific lipoprotein fractions.

In summary, tart cherry-enriched diets were associated with significantly increased hepatic PPAR- $\alpha$ expression, reduced hepatic lipid accumulation, reduced blood lipids, and reduced fasting glucose and reduced hyperinsulinemia. In addition, tart cherry diets were associated with increased expression and activity of a fat oxidizing enzyme, ACO, and with enhanced plasma antioxidant capacity. As a rich wholefood source of anthocyanins, tart cherry-enriched diets may modify several key risk indicators for Type 2 diabetes. Further studies are needed in human subjects with metabolic syndrome to ascertain the degree and spectrum of tart cherry-derived clinical benefits. 


\section{ACKNOWLEDGMENTS}

This study was funded by an unrestricted grant from the Cherry Marketing Institute and by the Gayle-Halperin Kahn Professorship in Integrative Medicine. The Cherry Marketing Institute did not participate in the data analysis or manuscript preparation.

\section{REFERENCES}

1. Grundy SM, Hansen B, Smith SC Jr, Cleeman JI, Kahn RA: Clinical management of metabolic syndrome: report of the American Heart Association/National Heart, Lung, and Blood Institute/ American Diabetes Association conference on scientific issues related to management. Arterioscler Thromb Vasc Biol 2004;24: e19-e24.

2. Cignarella A, Nastasi M, Cavalli E, Puglisi L: Novel lipid-lowering properties of Vaccinium myrtillus L. leaves, a traditional antidiabetic treatment, in several models of rat dyslipidaemia: a comparison with ciprofibrate. Thromb Res 1996;84:311-322.

3. Finne Nielsen IL, Elbol Rasmussen S, Mortensen A, et al: Anthocyanins increase low-density lipoprotein and plasma cholesterol and do not reduce atherosclerosis in Watanabe heritable hyperlipidemic rabbits. Mol Nutr Food Res 2005;49:301-308.

4. Kadar A, Robert L, Miskulin M, Tixier JM, Brechemier D, Robert AM: Influence of anthocyanoside treatment on the cholesterolinduced atherosclerosis in the rabbit. Paroi Arterielle 1979;5: 187-205.

5. Xia X, Ling W, Ma J, et al:: An anthocyanin-rich extract from black rice enhances atherosclerotic plaque stabilization in apolipoprotein E-deficient mice. J Nutr 2006;136:2220-2225.

6. Park MY, Lee KS, Sung MK: Effects of dietary mulberry, Korean red ginseng, and banaba on glucose homeostasis in relation to PPAR-alpha, PPAR-gamma, and LPL mRNA expressions. Life Sci 2005; 77:3344-3354.

7. Valcheva-Kuzmanova S, Kuzmanov K, Mihova V, Krasnaliev I, Borisova P, Belcheva A: Antihyperlipidemic effect of Aronia melanocarpa fruit juice in rats fed a high-cholesterol diet. $\underline{\text { Plant }}$ Foods Hum Nutr 2007;62:19-24.

8. Munoz-Espada AC, Watkins BA: Cyanidin attenuates PGE2 production and cyclooxygenase-2 expression in LNCaP human prostate cancer cells. J Nutr Biochem 2006;17:589-596.

9. Xia M, Hou M, Zhu H, et al.: Anthocyanins induce cholesterol efflux from mouse peritoneal macrophages: the role of the peroxisome proliferator-activated receptor $\gamma$-liver X receptor $\alpha$ ABCA1 pathway. J Biol Chem 2005;280:36792-36801.

10. Campbell IW: The clinical significance of PPAR gamma agonism. Curr Mol Med 2005;5:349-363.

11. Nehlin JO, Mogensen JP, Petterson I, et al.: Selective PPAR agonists for the treatment of type 2 diabetes. Ann N Y Acad Sci 2006;1067:448-453.

12. van Raalte DH, Li M, Pritchard PH, Wasan KM: Peroxisome proliferator-activated receptor (PPAR)-alpha: a pharmacological target with a promising future. Pharm Res 2004;21:1531-1538.

13. Blando F, Gerardi C, Nicoletti I: Sour cherry (Prunus cerasus L) anthocyanins as ingredients for functional foods. $\underline{\text { B Biomed }}$ Biotechnol 2004;2004:253-258.

14. Chandra A, Rana J, Li Y: Separation, identification, quantification, and method validation of anthocyanins in botanical supple- ment raw materials by HPLC and HPLC-MS. $J$ Agric Food Chem 2001;49:3515-3521.

15. Kotchen TA, Zhang HY, Covelli M, Blehschmidt N: Insulin resistance and blood pressure in Dahl rats and in one-kidney, oneclip hypertensive rats. Am J Physiol 1991;261:E692-E697.

16. Reaven GM, Twersky J, Chang H: Abnormalities of carbohydrate and lipid metabolism in Dahl rats. Hypertension 1991;18:630635.

17. Reaven GM, Twersky J, Ho H, Chang H: Hypertriglyceridemia in Dahl rats: effect of sodium intake and gender. $\underline{\text { Horm Metab Res }}$ 1991;23:44-45.

18. Sechi LA: Mechanisms of insulin resistance in rat models of hypertension and their relationships with salt sensitivity. J Hypertens 1999;17:1229-1237.

19. Mondon CE, Plato PA, Dall'Aglio E, Sztalryd C, Reaven G: Mechanism of hypertriglyceridemia in Dahl rats. Hypertension 1993;21:373-379.

20. Hirano T, Ebara T, Furukawa S, Nagano S, Takahashi T: Mechanism of hypertriglyceridemia in Dahl salt-sensitive rats, an animal model of spontaneous nephrotic syndrome. Metabolism 1994;43:248-256.

21. Donnelly R, Plato PA, Chang H, Reaven GM: Effects of gemfibrozil on triglyceride metabolism in Dahl salt-sensitive rats. $\underline{J}$ Pharmacol Exp Ther 1994;270:809-813.

22. Kurowski TG, Saha AK, Cunningham BA, et al.: Malonyl coenzyme A and adiposity in the Dahl salt-sensitive rat: effects of pioglitazone. Metabolism 1996;5:519-525.

23. O'Donnell MP, Kasiske BL, Katz SA, Schmitz PG, Keane WF: Lovastatin but not enalapril reduces glomerular injury in Dahl salt-sensitive rats. Hypertension 1992;20:651-658.

24. Wilson TW, Alonso-Galicia M, Roman RJ: Effects of lipid-lowering agents in the Dahl salt-sensitive rat. Hypertension 1998;31: 225-231.

25. Kirakosyan A, Seymour E, Kaufman PB, Warber S, Bolling S, Chang SC: Antioxidant capacity of polyphenolic extracts from leaves of Crataegus laevigata and Crataegus monogyna (hawthorn) subjected to drought and cold stress. J Agric Food Chem 2003;51:3973-3976.

26. Livak KJ, Schmittgen TD: Analysis of relative gene expression data using real-time quantitative PCR and the 2(-Delta Delta C(T)) method. Methods 2001;25:402-408.

27. Folch J, Lees M, Sloane Stanley GH: A simple method for the isolation and purification of total lipides from animal tissues. $\underline{J}$ Biol Chem 1957;226:497-509.

28. Ullman AH, White HB $3^{\text {rd: }}$ Assay of fatty acid synthase using a bicyclic dione as substrate. Methods Enzymol 1981;72:303-306.

29. Small GM, Burdett K, Connock MJ: A sensitive spectrophotometric assay for peroxisomal acyl-CoA oxidase. Biochem J 1985;227:205-210.

30. Gee MK, Zhang L, Rankin SE, Collins JN, Kauffman RF, Wagner JD: Rosiglitazone treatment improves insulin regulation and dyslipidemia in type 2 diabetic cynomolgus monkeys. Metabolism 2004;53:1121-1125.

31. Itoh H, Doi K, Tanaka T, et al.: Hypertension and insulin resistance: role of peroxisome proliferator-activated receptor gamma. Clin Exp Pharmacol Physiol 1999;26:558-560.

32. Laplante M, Sell H, MacNaul KL, Richard D, Berger JP, Deshaies Y: PPAR-gamma activation mediates adipose depot-specific effects on gene expression and lipoprotein lipase activity: mecha- 
nisms for modulation of postprandial lipemia and differential adipose accretion. Diabetes 2003;52:291-299.

33. Ramachandran U, Kumar R, Mittal A: Fine tuning of PPAR ligands for type 2 diabetes and metabolic syndrome. Mini Rev Med Chem 2006;6:563-573.

34. Yamauchi T, Hara K, Miki H, Kadowaki T: [The mechanisms by which PPAR gamma regulates fat storage and insulin sensitivity]. Nippon Rinsho 2001;(59 Suppl 2):489-497.

35. Yang B, Brown KK, Chen L, et al.: Serum adiponectin as a biomarker for in vivo PPARgamma activation and PPARgamma agonist-induced efficacy on insulin sensitization/lipid lowering in rats. BMC Pharmacol 2004;4(1):23.

36. Zierath JR, Ryder JW, Doebber T, et al.: Role of skeletal muscle in thiazolidinedione insulin sensitizer (PPARgamma agonist) action. Endocrinology 1998;139:5034-5041.

37. Lee $\mathrm{CH}$, Olson P, Evans RM: Minireview: lipid metabolism, metabolic diseases, and peroxisome proliferator-activated receptors. Endocrinology 2003;144:2201-2207.
38. Tsuda T, Horio F, Uchida K, Aoki H, Osawa T: Dietary cyanidin 3-O-beta-D-glucoside-rich purple corn color prevents obesity and ameliorates hyperglycemia in mice. J Nutr 2003;133:2125-2130.

39. Xia M, Ling WH, Ma J, Kitts DD, Zawistowski J: Supplementation of diets with the black rice pigment fraction attenuates atherosclerotic plaque formation in apolipoprotein $\mathrm{E}$ deficient mice. J Nutr 2003;133:744-751.

40. Jayaprakasam B, Olson LK, Schutzki RE, Tai MH, Nair MG: Amelioration of obesity and glucose intolerance in high-fat-fed C57BL/6 mice by anthocyanins and ursolic acid in Cornelian cherry (Cornus mas). J Agric Food Chem 2006;54:243-248.

41. Kelley DS, Rasooly R, Jacob RA, Kader AA, Mackey BE: Consumption of Bing sweet cherries lowers circulating concentrations of inflammation markers in healthy men and women. $\underline{J \text { Nutr }}$ 2006;136:981-986.

42. Seymour EM, Parikh RV, Singer AA, Bolling SF: Moderate calorie restriction improves cardiac remodeling and diastolic dysfunction in the Dahl-SS rat. J Mol Cell Cardiol 2006;41:661-668. 